\title{
A POLÍTICA DE FORMAÇÃO DE PROFESSORES: O ESTADO DA ARTE SOBRE O PIBID NA PÓS-GRADUAÇÃO EM EDUCAÇÃO
}

\author{
LA POLÍTICA DE FORMACIÓN DE PROFESORES: EL ESTADO DEL ARTE SOBRE \\ EL PIBID EN LA POST-GRADUACIÓN EN EDUCACIÓN
}

\author{
THE POLICY OF TEACHER TRAINING: THE STATE OF ART ON THE PIBID IN \\ POSTGRADUATE EDUCATION
}

\author{
Halisson Keliton Ramos dos SANTOS ${ }^{1}$ \\ Michele Silva SACARDO ${ }^{2}$
}

RESUMO: O presente estudo trata de uma pesquisa bibliográfica nos Programas de PósGraduação em Educação da região Centro-Oeste do Brasil, de 2009 a 2015, referente à temática Pibid, cujo objetivo central foi realizar um mapeamento da produção do conhecimento científico sobre o programa. Os resultados evidenciaram que as pesquisas sobre a temática têm priorizado os participantes do programa em alguns cursos de licenciatura. Os trabalhos analisados identificaram que o Pibid tem contribuído para a formação dos licenciandos, mesmo de forma pontual. No entanto, ter um olhar crítico e amplo sobre as políticas educacionais, sobretudo as políticas de formação de professores, nos possibilita compreender que não há soluções fáceis para problemas complexos como os que temos na formação de professor.

PAlAVRAS-CHAVE: Pibid. Formação de professores. Políticas de formação de professores. Estado da arte. Produção acadêmica.

RESUMEN: El presente estudio trata de una investigación bibliográfica en los Programas de Postgrado en Educación de la región centro oeste de Brasil, de 2009 a 2015, referente a la temática Pibid, cuyo objetivo central fue realizar un mapeo de la producción del conocimiento científico sobre el programa. Los resultados evidenciaron que las investigaciones sobre la temática han priorizado los participantes del programa en algunos cursos de licenciatura. Los trabajos analizados identificaron que el Pibid ha contribuido para la formación de los licenciandos, incluso de forma puntual. Sin embargo, tener una mirada crítica y amplia sobre las políticas educativas, sobre todo las políticas de formación de profesores, nos permite comprender que no hay soluciones fáciles para problemas complejos como los que tenemos en la formación de profesores.

PALABRAS CLAVE: Pibid. Formación de profesores. Políticas de formación de profesores. Estado del arte. Producción académica.

\footnotetext{
${ }^{1}$ Universidade Federal de Goiás (UFG), Jataí - GO - Brasil. Mestrando no Programa de Pós-Graduação em Educação (PPGE/UFG/REJ). ORCID: <http://orcid.org/0000-0002-9634-6553>. E-mail: halissonksantos@gmail.com

${ }^{2}$ Universidade Federal de Goiás (UFG), Jataí - GO - Brasil. Professora Doutora do Programa de Pós-Graduação em Educação (PPGE/UFG/REJ). ORCID: <http://orcid.org/0000-0003-4193-3766>. E-mail: michelesacardosilva@gmail.com
}

RPGE- Revista on line de Política e Gestão Educacional, Araraquara, v. 22, n. 3, p. 1168-1181, set./dez., 2018. E-ISSN:1519-9029. DOI: $10.22633 /$ rpge.v22i3.11404 
ABSTRACT: This study deals with a bibliographic research in the Post-Graduate Programs in Education of the Mid-West region of Brazil, from 2009 to 2015, referring to the Pibid theme, whose central objective was to map the production of scientific knowledge about program. The results showed that research on the subject has prioritized program participants in some undergraduate courses. The analyzed works identified that the Pibid has contributed to the training of the teaching students, even punctually. However, having a critical and broad view on educational policies, especially teacher training policies, enables us to understand that there are no easy solutions to complex problems such as those of teacher training.

KEYWORDS: Pibid. Teacher training. Teacher training policies. State of the art. Academic production.

\section{Introdução}

Este estudo discute a formação de professores e o Pibid (Programa Institucional de Bolsa de Iniciação à Docência), cujo objetivo central foi realizar um mapeamento do Pibid como política pública de formação inicial de professores nos Programas de Pós-Graduação em Educação da região Centro-Oeste, no período de 2009 a 2015.

Para tanto, realizaremos uma breve discussão sobre o atual cenário da formação de professores, mais especificamente das políticas públicas de formação de professores com o foco no Pibid, e, em seguida, apresentaremos o corpus de análise.

Empenhamos em trazer neste trabalho, em linhas gerais, o que estamos denominando de pesquisa de caráter bibliográfico, especialmente sobre as produções científicas de teses e dissertações. Nessas produções científicas, podem ser analisados aspectos como a metodologia, a teoria, o paradigma, a técnica, a bibliometria e a epistemologia (SACARDO, 2012). Mais especificamente, na perspectiva de uma epistemologia crítica, a produção científica deve ser entendida tanto como produção social, influenciada pelas condições históricas, quanto por seu efeito transformador dessas mesmas condições e da própria prática da pesquisa. Nesse sentido, os trabalhos científicos não devem apenas ser analisados como fatos decorrentes e inseridos em determinadas circunstâncias, mas também devem ter seus resultados avaliados à luz de necessidades e objetivos sociais e interesses que os explicitam. Ou seja, não basta a constatação de suas características gerais, é fundamental, portanto, averiguar qual sua pertinência e significado para o desenvolvimento social e sua relação política com esse desenvolvimento (SACARDO; SILVA; SANCHEZ-GAMBOA, 2015).

As pesquisas denominadas de 'estado da arte' ou 'estado do conhecimento', segundo Ferreira (2002, p. 257), por serem 
[...] de caráter bibliográfico, elas parecem trazer em comum o desafio de mapear e de discutir uma certa produção acadêmica em diferentes campos do conhecimento, tentando responder que aspectos e dimensões vêm sendo destacados e privilegiados em diferentes épocas e lugares, de que formas e em que condições têm sido produzidas certas dissertações de mestrado, teses de doutorado, publicações em periódicos e comunicações em anais de congressos e de seminários.

Essas pesquisas podem, pois, possibilitar o conhecimento da área que se pretende investigar, bem como contribuir para a discussão de determinada produção científica. Podem ainda levantar evidências, tendências, potencialidades, modismos e padrões (SACARDO, 2012), o que faz delas um formato metodológico importante na produção do conhecimento na Educação.

\section{A política de formação de professores}

Consideramos a política de formação de professores como síntese de múltiplas determinações, buscamos compreendê-la inserida no atual modo de produção (capitalista), marcado pela fragmentação e alienação do trabalho, mercadorização da educação e políticas neoliberais. No tocante ao objeto, formação de professores, busca-se referendá-lo como elemento inserido em uma totalidade contraditória que se move pela incontrolável transformação histórica, colocando em evidência as diferentes forças e fatores que determinam e constituem a complexidade social. Assim, o nosso ponto de partida é um referencial crítico no campo da educação por entender que, na atualidade, faz-se necessário um posicionamento epistemológico político.

Para situarmos o atual estado da formação de professores e sua política, faz-se necessária uma breve referência ao final da década de 1970 e início dos anos 1980. Esse período, sobretudo a década de 1980, marca a luta pela democratização da sociedade brasileira. O pensamento tecnicista orientou a educação principalmente nos anos de 1960 e 1970, período marcado pelo início do regime militar no Brasil. Esse modelo foi contraposto nos debates da década de 1980, momento de abertura política, pelas concepções críticas da educação que se caracterizam por recuperar o professor como sujeito histórico de sua própria prática e centrar na categoria trabalho como orientadora dos estudos teóricos de análise do processo de trabalho (FREITAS, 2002).

Na década subsequente (1990), antagonicamente, o modelo tecnicista é retomado com toda força na educação do nosso país com ênfase nos conteúdos, habilidades e competências, 
orientando principalmente as políticas educacionais, em especial as direcionadas para a formação de professor (FREITAS, 2002).

Na América Latina e, em específico, no Brasil, a interlocução com os Organismos Multilaterais (OMs), principalmente com o Banco Mundial, vem ganhando força e tem o seu ápice no governo de Fernando Henrique Cardoso (FHC) em meados de 1990. Porém, essa interlocução foi mantida, aprofundada e aprimorada pelos dois governos subsequentes. Mas é no governo de FHC que foram colocadas as condições para a reforma na educação, seguindo uma lógica de expansão econômica e tecnológica sob orientação neoliberalista, supondo a superação da ineficácia pela eficácia e competência, desqualificação da escola pública às custas da culpabilização do professor e principalmente tecendo duras críticas à sua formação (EVANGELISTA, 2013). "Especialmente após a década de 1990, o foco no professor e em sua formação passou a ser elemento decisivo a uma educação de qualidade e, portanto, às mudanças esperadas pelo mercado [...]” (BERNARDES; MAGALHÃES, 2013, p. 1).

Segundo Freitas (2007), a configuração da formação de professores, principalmente as políticas de formação de educadores, tem respondido as reformas educacionais orientadas pelos OMs, a exemplo da expansão do ensino superior na década de 1990, que conduziu a flexibilização das ofertas de curso superior de formação nas instituições privadas e institutos de educação, cursos especiais e a distância, como forma de responder à demanda crescente pela formação superior. "As implicações desta organização do ensino superior foram exaustivamente denunciadas nos últimos anos, tanto pelas entidades educacionais quanto por estudiosos da área" (FREITAS, 2007, p. 1226).

Essas reformas, como são perceptíveis no atual momento, não atendem a uma perspectiva de acesso irrestrito e de qualidade das camadas populares ao ensino superior, mas fundamentalmente a interesses puramente econômicos, ou seja, formar contingente humano para servir às demandas do mercado de trabalho.

Para Kuenzer (1991), a formação docente está ancorada em uma divisão entre trabalho intelectual e trabalho manual; e ainda o enfrentamento de questões como essas tem sido dificultado por políticas que não defendem uma democratização do saber, que não têm assegurado à classe trabalhadora o acesso irrestrito à educação (conhecimento teórico) e ao trabalho (conhecimento prático) sem dicotomia e sem privilegiar uma classe ou outra.

Segundo Freitas (2014), o Ministério da Educação (MEC) tem se pautado por ações de caráter compensatório, visto que as políticas de formação de professores têm se precipitado ao tratar os problemas pela sua consequência/sintomas, e não pela causa/raiz. Essas políticas têm defendido a ideia do fim da licenciatura por curso próprio ou o seu aligeiramento como forma 
de suprir carências de professores em áreas críticas do ensino por meio de programas emergentes como o Pibid e a Prodocência ${ }^{3}$. Nesse sentido, a autora alerta que

Hoje, como em 1997, reafirma-se que a raiz do problema da escassez de professores está na crescente desvalorização econômica e social do professor, como resultado das péssimas condições de trabalho e salários e da inexistência de um plano de carreira que valorize a função docente e o trabalho pedagógico profissional. Todo o esforço que vem sendo feito por diferentes universidades na direção da preparação e formação de professores esbarra sempre na dura realidade que esses profissionais enfrentam em seu campo de trabalho na escola pública, historicamente degradada e desqualificada como espaço de formação das novas gerações. (FREITAS, 2014, p. 19)

A constatação da perda de interesse pela carreira docente está presente nos dados de procura por cursos de licenciatura nas universidades brasileiras. Na primeira década dos anos 2000, os cursos de licenciatura tiveram reduzido o número de procura, principalmente se comparado com a crescente demanda por bacharelados (SANTANA, 2015).

Assim, ao debruçarmos sobre a temática, encontramos uma contradição, pois "o atual cenário está repleto de problemas bem velhos", ou seja, a formação de professores está há 30 anos marcada por um aligeiramento na formação, pela exacerbação do neotecnicismo. A escola tem se tornado um campo de pouca procura ou recusa dos acadêmicos que não querem atuar nesse espaço. E, ainda, tem como pano de fundo ações, programas e políticas que precisam ser repensados a partir de ações para o presente momento e também a longo prazo.

\section{O Pibid como política de formação de professores}

Referindo-se ao cenário da formação de professores, surgem vários problemas, destacando-se, entre eles, a recusa da escola como possibilidade de futuro campo de trabalho pelos acadêmicos em formação; o aligeiramento e a desqualificação da formação inicial; pouco diálogo com a realidade concreta da educação básica ou desenvolvida de forma tardia nos currículos; pouco diálogo com as especificidades da escola; desvalorização social, econômica e política da docência.

Esse cenário, marcado por formas de organização próprias do atual modelo econômico, tem atingido gravemente a educação, mas, sobremaneira, a formação de professores. O professor, do ponto de vista oficial, passa a desempenhar um importante papel

${ }^{3}$ O Programa de Consolidação das Licenciaturas é uma ação da Capes cuja finalidade é o fomento à inovação e à elevação da qualidade dos cursos de formação para o magistério da Educação Básica, na perspectiva de valorização da carreira docente (BRASIL, 2012). 
nesse contexto, ou seja, a sua formação inicial e continuada necessita de "qualificação", uma vez que recai sobre ele a responsabilização pelos sucessos e insucessos educacionais em nosso país. Porém, a docência não tem despertado na juventude brasileira o interesse por ingressar ou se manter nessa área. O resultado dessa conjuntura tem sido um dos grandes problemas que assolam a educação no Brasil, a escassez de professores.

Com efeito, Freitas (2014) afirma que o Pibid surge a partir do quadro de professores apresentado em 2007, que revelava que os docentes do ensino fundamental e médio atuavam em disciplinas que sua formação não os habilitou. Dessa forma, o quadro de "escassez de professores" levou o MEC a instituir o Pibid em 2007, sob coordenação da Capes. O Pibid está entre os programas da Diretoria de Formação de Professores da Educação Básica - DEB, também vinculada à Capes.

Assim, o Pibid surge com a responsabilidade de atender às difíceis tarefas e objetivos que lhe são determinados, para além de incentivar os estudantes a optarem pela licenciatura, direcionando sua formação para áreas em que a carência de professores representava uma necessidade emergente: biologia, química, física e matemática, consideradas como prioridade.

Além disso, deveria contribuir para o aumento das médias das escolas participantes do Exame Nacional do Ensino Médio (Enem). A criação deste programa atendia então ao plano de metas "Compromisso Todos pela Educação", previsto no Plano de Desenvolvimento da Educação (PDE), em busca de se elevar o Índice de Desenvolvimento da Educação Básica (Ideb) em âmbito nacional para a média 6, a ser alcançada até 2022, ano do bicentenário da Independência do Brasil (FREITAS, 2014).

Dessa forma, o programa objetivava fomentar a iniciação à docência, contribuir para o aperfeiçoamento da formação de docentes em nível superior, elevação da qualidade da escola básica pública, contribuir para a relação teoria e prática, avizinhar universidade e escola. Como caminho para atingir seus objetivos, o acadêmico é inserido desde o início da sua formação no dia a dia e rotina da escola, sob orientação de professores das IES e professor supervisor da própria escola (BRASIL, 2013).

O Pibid cresceu e se constituiu como uma importante iniciativa no campo da formação de professores no Brasil. Embora o programa tenha seus limites, também aponta possibilidades de contribuição, mesmo pontual, para a formação de professores nas diversas áreas do conhecimento.

Hoje, diante do contexto político e econômico no Brasil, o programa tem sofrido com possibilidade de interrupção em suas atividades. Mas essas investidas não ocorrem sem resistência de movimentos por todo o país defendendo a permanência e ampliação do 
programa. Os pibidianos, segundo Freitas (2011, p. 10), "são os estudantes, os professores e a universidade que apoiam o programa. Eles também fazem parte dessa luta histórica numa perspectiva de apontar o futuro para a formação de professores”. Entretanto, não podemos deixar de expressar que o que queremos para o futuro da formação de professores são políticas de Estado, extensivas a todos os licenciandos, professores e universidades deste país. Políticas que superem definitivamente o caráter paliativo e pontual das reformas educacionais em todos os âmbitos.

É exatamente pelo fato de o Pibid estar causando euforia e aderência entre os estudantes de licenciatura e os professores das IES e escolas pelo Brasil, que falamos da necessidade de uma análise crítica desse programa, que nos permita apontar a direção que queremos para políticas de formação de professores. Pensando em ferramentas para tais análises, não podemos abrir mão da dialética marxiana. Isso porque o Pibid nasce no seio da atual sociedade e faz parte de um projeto político de educação que tem apresentado dificuldades para uma formação preocupada com as necessidades da classe trabalhadora.

Mesmo não sendo esse o objetivo deste artigo, não poderia deixar de apresentar alguns pontos que podem instigar o debate, pois em análises feitas a partir de documentos oficiais do Pibid temos identificado um claro alinhamento com os pressupostos epistemológicos hegemônicos atualmente no campo dos estudos sobre formação de professores. 0 programa também está referendado em autores como Nóvoa, Shön e outros, responsáveis pela divulgação no Brasil da pedagogia do professor reflexivo, de ramificação escolanovista. As implicações e os desdobramentos epistemológico e pedagógico dessas pedagogias contemporâneas são inúmeros, visto que

de pouco ou nada servirá a defesa da tese de que formação de professores no Brasil deva ser feita nas universidades, se não for desenvolvida uma análise crítica da desvalorização do conhecimento escolar, científico, teórico, contida nesse ideário que se tornou dominante no campo da didática e da formação de professores, isto é, esse ideário representado por autores como Schön, Tardif, Perrenoud, Zeichner, Nóvoa e outros. De pouco ou nada servirá mantermos a formação de professores nas universidades se o conteúdo dessa formação for maciçamente reduzido ao exercício de uma reflexão sobre os saberes profissionais, de caráter tácito, pessoal, particularizado, subjetivo etc. De pouco ou nada adiantará defendermos a necessidade de os formadores de professores serem pesquisadores em educação, se as pesquisas em educação se renderem ao "recuo da teoria". (DUARTE, 2003, p. 12; grifos no original) 
Contudo, essas pedagogias estão assentadas em princípios epistemológicos que desvalorizam o conhecimento teórico/científico/acadêmico e numa pedagogia que desvaloriza o saber escolar. Nesse sentido, elas se aproximam em muito do escolanovismo clássico de inspiração deweyana (DUARTE, 2003).

\section{Metodologia}

A partir desse breve panorama sobre o Pibid e as problemáticas que perpassam a formação de professores no Brasil, este estudo realiza um levantamento da produção do conhecimento sobre o Pibid nos Programas de Pós-Graduação em Educação/ PPGE da região Centro-Oeste do Brasil, cuja busca compreende os anos de 2009 a 2015. As fontes selecionadas foram as dissertações e teses sobre Pibid nos PPGE da UFG (Universidade Federal de Goiás), PUC-GO (Pontifícia Universidade Católica de Goiás), UNB (Universidade de Brasília), UCB (Universidade Católica de Brasília), UFMT (Universidade Federal do Mato Grosso), UNEMAT (Universidade do Estado do Mato Grosso), UFMS (Universidade Federal do Mato Grosso do Sul), UFGD (Universidade Federal da Grande Dourado), UEMS (Universidade Estadual do Mato Grosso do Sul) e UCDB (Universidade Católica Dom Bosco).

O levantamento foi realizado nos bancos de teses e dissertações da Capes (Coordenação de Pessoal de Nível Superior) e nas bibliotecas digitais de cada programa. Foram selecionados trabalhos que contivessem a palavra "Pibid" nos títulos e/ou nos resumos. Desse modo, identificamos oito dissertações de Mestrado Acadêmico e uma de Mestrado Profissional sobre Pibid, em cinco das dez universidades pesquisadas e nenhuma tese de 2009 a 2015 (Tabela 1).

Tabela 1 - Quantidade de dissertações sobre o Pibid, por ano, estado e PPGE defendidas de 2009 a 2015

\begin{tabular}{c|cc|cc|cccc|cc|c}
\hline \multicolumn{10}{c}{ An0 } & \multicolumn{10}{c}{ Estados da Região Centro-0este e 0 Distrito Federal } \\
\hline & \multicolumn{2}{|c}{ G0 } & \multicolumn{2}{c|}{ MT } & \multicolumn{3}{c|}{ MS } & \multicolumn{2}{c}{ DF } & Total \\
\hline PPGE & UFG & PUC & UFMT & UNEMAT & UFMS & UFGD & UEMS & UCDB & UNB & UCB & \\
\hline 2015 & 1 & - & - & - & - & - & - & - & 1 & 1 & 3 \\
2014 & - & - & - & - & - & - & - & 2 & 1 & - & 3 \\
2013 & - & - & 1 & - & - & - & - & - & 2 & - & 3 \\
2012 & - & - & - & - & - & - & - & - & - & - & - \\
2011 & - & - & - & - & - & - & - & - & - & - & - \\
2010 & - & - & - & - & - & - & - & - & - & - & - \\
2009 & - & - & - & - & - & - & - & - & - & - & - \\
\hline Total & 1 & - & 1 & - & - & - & - & 2 & 4 & 1 & 9 \\
\hline
\end{tabular}

Fonte: Elaboração dos autores (JATAÍ, 2017) 
No período de 2009 a 2015, nove dissertações tomam o Pibid como objeto de estudo. De acordo com a tabela 1, podemos identificar que os trabalhos na região Centro-Oeste só começam a ser defendidos em 2013, ou seja, três anos após o início das atividades do Pibid em 2009. "O primeiro edital do Pibid foi publicado em 13 dezembro de 2007, na página 40, seção 3, do n. 239 do Diário Oficial da União. A seleção de propostas ocorreu em 2008, mas os projetos iniciaram suas atividades em 2009” (SANTANA, 2015, p. 48).

Nesse sentido, os estados que tiveram pesquisas sobre o programa foram nessa ordem: Distrito Federal com cinco, sendo quatro deles na UNB e um na UCB; Mato Grosso do Sul com dois, ambos na UCDB; Mato Grosso teve um na UFMT; e Goiás também com um na UFG.

\section{A pesquisa empírica - o estado da arte sobre o Pibid}

A seguir, por meio de uma síntese, apresentamos os pontos de convergência, divergência e particularidades dos trabalhos investigados. Nas dissertações, buscamos destacar objetivos, metodologias, resultados e descobertas e as conclusões dos autores. Nos resumos que não foram possíveis encontrar essas informações, fez-se necessário adentrar no corpo do texto.

Os trabalhos apresentados por Moura (2013), Dantas (2013), Oliveira (2014), Santos (2014), Medeiros (2015) e Silva (2015) buscam apresentar ou discutir quais as implicações das ações do Pibid na formação dos participantes do programa. Já as pesquisas de Barros (2013), Cellos (2014) e Santana (2015) apresentam discussões diferentes: Barros (2014) tem interesse em investigar a relação do Pibid e a permanência dos licenciandos no curso de formação; Cellos (2014) utiliza os participantes do programa como informantes e quer saber sobre o uso das Tecnologias da Informação e Comunicação (TICs) e de que maneira elas se configuram como um diferencial no processo de formação dos licenciandos de Geografia no contexto do Pibid/UFMT; e Santana (2015) analisa o processo de implementação do subprojeto Pibid na IES (Instituição de Ensino Superior) e sua relação com o Pibid.

Existe uma convergência desses trabalhos, principalmente no que se refere à metodologia da pesquisa: todos os trabalhos apresentados aqui realizam uma investigação de abordagem qualitativa, sendo o estudo de caso a tipologia mais utilizada. Entre os instrumentos de coleta de dados mais recorrentes estão as entrevistas semiestruturadas e os questionários. Para a análise dos dados empíricos, a técnica mais enfatizada é a de análise de conteúdo. A análise documental dos subprojetos, diretrizes da formação de professores, 
relatórios de atividades, entre outros, também são muito utilizados. Os estudos de forma geral são de natureza teórica e empírica. Já a metodologia empregada nos estudos sobre o Pibid, principalmente os instrumentos de coleta de dados como entrevistas e questionários, mostra uma preocupação dos pesquisadores no tocante à visão dos participantes sobre as ações desenvolvidas no projeto.

Há ainda uma variedade de focos dos estudos em relação aos participantes pesquisados: os trabalhos abrangem licenciandos bolsistas, coordenadores de área, os exbolsistas de iniciação à docência, professores da escola, supervisores do programa e alunos não bolsistas. Documentos como relatórios de atividade do subprojeto também são utilizados como fonte de pesquisa.

Os estudos analisaram ações e experiências que contemplaram os cursos de Pedagogia, Física, Biologia, Geografia e Química; os cursos de História, Letras, Filosofia, Artes e Educação Física não foram contemplados nos trabalhos. Entre os estudos, um não indicou qual o curso investigado. O número reduzido ou a inexistência de trabalhos sobre as áreas de conhecimento citadas não é uma particularidade desse estudo. Gatti et al. (2014), ao realizarem um mapeamento da produção do conhecimento sobre Pibid, também identificaram que as áreas de Química, Geografia, História, Língua Espanhola, Filosofia, Artes e Educação Física foram contempladas com um número menor de trabalhos.

Os resultados nos trabalhos analisados, de forma geral, apontaram para as ações formativas principalmente no campo da prática pedagógica. Mas alguns estudos revelaram resultados que merecem destaques, como unidade entre teoria e prática, aproximação entre IES e escolas de educação básica, aprendizagem de conhecimentos práticos, reflexão sobre prática, entre outros.

$\mathrm{Na}$ atual conjuntura, a formação de professores encontra-se marcada também pela pouca articulação entre teoria e prática. As pesquisas analisadas, na sua maioria, têm apresentado que o Pibid proporciona articulação entre teoria e prática, o que pode indicar que o programa esteja contribuindo para a qualificação da formação de professores. Limonta e Silva (2013, p. 173) chamam a atenção afirmando que "[...] para um ensino de qualidade, se faz necessária a constituição de uma sólida base teórico-epistemológica no percurso formativo que se materializa no processo de trabalho".

Aqui é preciso destacar que a relação entre teoria e prática é objetivo do Pibid e que aparentemente, como apontam os trabalhos analisados, está sendo alçado. No entanto, precisamos indagar sobre qual concepção de relação teoria e prática estão assentados os objetivos do programa, pois, como já mencionado em outro momento, os pressupostos 
teórico-metodológicos que embasam a proposta pedagógica do Pibid estão sob uma epistemologia e pedagogia que relegam à teoria um papel secundário, desconsiderando, em última análise, a relação dialética e de unicidade entre teoria e prática. $\mathrm{O}$ desdobramento de uma formação de professores centrada em pedagogias que radicalizam a questão da importância da ação prática pode ser ainda um risco da ação docente pouco articular com o contexto social mais amplo e, nesse sentido, o que fica esquecido é o capital e suas leis totalizantes.

A pesquisa também aparece como estratégia na formação dos acadêmicos, mas a falta de uma análise mais aprofundada não nos permitiu identificar a concepção de pesquisa que está sendo apresentada pelos autores a partir de suas investigações.

No geral, um dado sobressaiu: os trabalhos concluíram que o Pibid tem contribuído para a formação de professores. Porém, alertam sobre o caráter emergencial do programa, marca das políticas educacionais no Brasil, que precisa ser superado, ou seja, dar lugar às políticas de Estado que pensem os atuais problemas da educação de forma articulada e ampla para verdadeiramente solucioná-los.

\section{Considerações finais}

O mapeamento da produção do conhecimento sobre o Pibid na Pós-Graduação em Educação no Centro-Oeste oportunizou-nos um panorama das investigações sobre essa temática nessa região. As pesquisas têm priorizado os participantes do programa em alguns cursos de licenciatura, o que mostra uma preocupação dos pesquisados com os impactos do programa nos bolsistas.

Quanto à tipologia, a mais empregada é o estudo de caso, o que não possibilita uma análise por parte das dissertações de forma mais ampla. Nesse sentido, podemos, a título de proposição, indicar pesquisas que usam outras tipologias de pesquisa, como as denominadas de "estados da arte", que podem contribuir para uma análise mais ampliada sobre o programa.

Sobre os trabalhos analisados, estes identificaram que o Pibid tem contribuído, mesmo que de forma pontual, para a formação dos licenciandos. No entanto, ter um olhar crítico e amplo sobre as políticas educacionais, especialmente sobre as políticas de formação de professor, nos possibilita compreender que não há soluções fáceis para problemas complexos, como os que temos na formação de professores.

Os trabalhos ainda têm alertado que o Pibid é uma política que, embora esteja contribuindo para a formação dos bolsistas participantes, não pode ser compreendida como 
redentora dos complexos problemas que envolvem a formação docente, e apontam na direção de superação de políticas paliativas, como o Pibid, no sentido de estas darem lugar a uma política que articule, entre outras coisas, formação inicial e continuada, valorização social e econômica, melhores salários e condição adequada de trabalho aos professores. Esses pontos comuns, em grande parte dos trabalhos sobre Pibid, já são reivindicados pelos educadores e fazem parte das lutas destes pela educação pública nos últimos 30 a 40 anos.

A necessidade de uma política global de formação e valorização dos profissionais da educação que contemple de forma articulada e prioritária a formação inicial, formação continuada e condições de trabalho, salários e carreira, com a concepção sócio-histórica do educador a orientá-la, faz parte das utopias e do ideário de todos os educadores e das lutas pela educação pública nos últimos 30 anos. (FREITAS, 2007, p. 1203)

A produção do conhecimento sobre Pibid nos Programas de Pós-Graduação em Educação, como no texto de Freitas (2007), coloca-nos o desafio de reivindicar uma política global para a formação de professores no nosso país. É possível inferir que as políticas educacionais, tanto pelo referencial teórico aqui adotado quanto pelos trabalhos analisados, não têm atacado verdadeiramente a raiz do problema, a sua causa, mas sim as suas consequências com programas emergenciais.

AGRADECIMENTOS: A Capes, pelo apoio financeiro.

\section{REFERÊNCIAS}

BARROS, G. de S. F. Análise do Programa Institucional de Bolsas de Iniciação à Docência e sua relação com a permanência nos cursos de licenciatura do Instituto Federal do Norte de Minas Gerais- Campus Salinas: limites e perspectivas. 2013. $132 \mathrm{f}$. Dissertação (Mestrado Profissional em Educação) - Faculdade de Educação, Universidade de Brasília, Brasília - DF, 2013.

BERNARDES, C. A. A.; MAGALHAES, S. M. O. Formação docente: contradições presentes nos projetos de sociedade em disputa. In: V EDIPE - Encontro Estadual de Didática e Prática de Ensino, 2013, Goiânia. Anais... Didática e Formação de professores: a qualidade da educação em debate, 2013. p. 1-15. Disponível em:

http://www2.unucseh.ueg.br/ceped/edipe/anais/vedipefinal/pdf/gt09/co\%20grafica/Cyntia\%20 Aparecida\%20de\%20Araujo\%20Bernardes.pdf. Acesso em: 05 out. 2017.

BRASIL. Programa de Consolidação das Licenciaturas - Prodocência, 2012. Disponível em: http://www.capes.gov.br/educacao-basica/prodocencia. Acesso em: 2 dez. 2017.

BRASIL. Portaria ${ }^{\circ}$ 096, de 18 de julho de 2013. Regulamento do Programa Institucional de Bolsas de Iniciação à Docência, 2013. Disponível em: 
https://www.capes.gov.br/images/stories/download/legislacao/Portaria_096_18jul13_Aprova RegulamentoPibid.pdf. Acesso em: 23 nov. 2017.

CELLOS, M. A. Licenciandos em geografia e o uso das TIC no programa de iniciação à docência-Pibid/UFMT. 2014. 112 f. Dissertação (Mestrado em Educação) - Faculdade de Educação, Universidade de Brasília, Brasília - DF, 2014.

DANTAS, L. K. Iniciação à docência na UFMT: contribuições do Pibid na formação de professores de Química. 2013. 188 f. Dissertação (Mestrado em Educação) - Faculdade de Educação, Universidade Federal de Mato Grosso, Cuiabá, 2013.

DUARTE, N. Conhecimento tácito e conhecimento escolar na formação do professor (porque Donald Schön não entendeu Luria). Educação \& Sociedade, v. 24, n. 83, 2003. Disponível em: http://www.scielo.br/pdf/\%0D/es/v24n83/a15v2483.pdf. Acesso em: 20 mar. 2017.

EVANGELISTA, O. Qualidade da educação pública: Estado e Organismos Multilaterais. In: LIBÂNEO, J. C.; SUANNO, M. V. R.; LIMONTA, S. V. (Org.). Qualidade da escola pública: políticas educacionais, didática e formação de professores. Goiânia: CEPED Publicações, 2013.

FERREIRA, N. S. A. A pesquisa denominada "Estado da Arte". Revista Educação e Sociedade, Campinas; Cedes; Unicamp, ano XXIII, n. 79, ago. 2002. Disponível em: http://www.scielo.br/pdf/es/v23n79/10857.pdf. Acesso em: 10 mar. 2017.

FREITAS, H. C. L. de Formação de professores no Brasil: 10 anos de embate entre projetos de formação. Educação e Sociedade. Campinas, v. 23, n. 80, p. 136 - 167, set./2002. Disponível em: http://www.cedes.unicamp.br. Acesso em: 15 mar. 2017.

FREITAS, H. C. L. de. (Nova) política de formação de professores: a prioridade postergada. Educação e Sociedade. Campinas, v. 28, n. 100 - Especial, p. 1203-1230, out./2007. Disponível em: http://www.cedes.unicamp.br. Acesso em: 10 mar. 2017.

FREITAS, H. C. L. de. Os desafios que a formação de professores propõe à universidade. In: FREITAS, D.; BAZON, F. V. M.; OZELO, H. F. B. (Orgs.). Iniciação à docência e formação continuada de professores. São Carlos: Suprema Gráfica e Editora, 2011.

FREITAS, H. C. L. de. O Pibid e as políticas de formação e valorização profissional do magistério. In: AYOUB, E.; PRADO, G. do V. T. (Orgs.). Pibid-UNICAMP: Construindo parcerias entre a universidade e a escola pública. Campinas, SP: Edições Leitura Crítica, 2014. (Coleção Formação docente em diálogo; v. 2).

GATTI, A. B.; ANDRÉ, M. E. D. A.; GIMENES, N. A. S.; FERRAGUT, L. Um estudo avaliativo do Programa Institucional de Bolsa de Iniciação à Docência (Pibid). São Paulo: FCC/SEP, 2014.

KUENZER, A. Z. Educação e trabalho no Brasil: o estado da questão. Brasília, DF: INEP; Santiago, REDUC, 1991.

LIMONTA, S. V.; SILVA, K. A. C. P. C. da. Formação de professores, trabalho docente e qualidade de ensino. In: LIBÂNEO, J. C., SUANNO, M. V. R.; LIMONTA, S. V. (Org.). 
Qualidade da escola pública: políticas educacionais, didática e formação de professores. Goiânia: CEPED Publicações, 2013.

MEDEIROS, J. L. O Pibid e a formação do professor de Ciências no Instituto Federal Goiano - Campus Rio Verde: avanços, limites e perspectivas. 2015. 196 f. Dissertação (Mestrado em Educação) - Universidade Federal de Goiás, Jataí.

MOURA, E. J. S. Iniciação à docência como política de formação de professores. 2013. 161 f. Dissertação (Mestrado em Educação) - Faculdade de Educação, Universidade de Brasília, Brasília - DF, 2013.

OLIVEIRA, E. A. da C. de. As ações do Pibid e a formação docente na perspectiva dos acadêmicos bolsistas da Pedagogia/ UCDB. 2014. 108 f. Dissertação (Mestrado em Educação) - Universidade Católica Dom Bosco, Campo Grande, 2014.

SACARDO, M. S. Estudo bibliométrico e epistemológico da produção em Educação Física na Região Centro-Oeste do Brasil. 2012.255 f. Tese (Doutorado em Educação) Universidade Federal de São Carlos, São Carlos, 2012

SACARDO, M. S.; SILVA, R. H. dos R.; SANCHEZ-GAMBOA, S. As análises epistemológicas na educação física: redescrevendo às redescrições? Não! Apenas aproveitando o ensejo da crítica. In: CHAVEZ-GAMBOA, M.; SANCHEZ-GAMBOA, S. (Org.). Produção do conhecimento na Educação Física: balanço, debates e perspectivas. Maceió: EDUFAL, 2015. p. 104-125.

SANTANA, L. L. de. Subprojeto Pibid de Física na UnB: implementação de uma política pública de formação de professores. 2015. 122f. Dissertação (Mestrado em Educação) Faculdade de Educação, Universidade de Brasília, Brasília - DF, 2015.

SANTOS, T. C. de S. dos. O Pibid e suas contribuições para o desenvolvimento profissional dos professores da educação básica. 2014. 121 f. Dissertação (Mestrado em Educação) - Universidade Católica Dom Bosco, Campo Grande, 2014.

SILVA, M. de L. de A. O programa institucional de bolsa de iniciação à docência e a formação do pedagogo: limites e potencialidades. 2015. $168 \mathrm{f}$. Dissertação (Mestrado em Educação) - Universidade Católica de Brasília, Brasília - DF, 2015.

\section{Como referenciar este artigo}

SANTOS, Halisson Keliton Ramos dos.; SACARDO Michele Silva. A política de formação de professores: o estado da arte sobre o Pibid na Pós-Graduação em Educação. Revista on line de Política e Gestão Educacional, Araraquara, v. 22, n. 3, p. 1168-1181, set./dez., 2018. E-ISSN:1519-9029. DOI: 10.22633/rpge.v22i3.11404

Submetido em: 24/05/2018

Aprovado em: 16/07/2018 